Received: 15 May 2017

Accepted: 21 September 2017

Published online: 17 October 2017

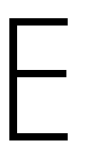

C N
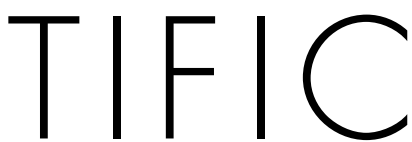

REP

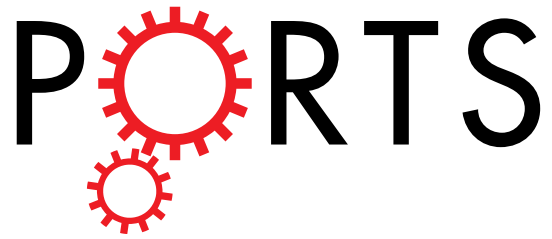

OPEN MiR-302b Suppresses

\title{
Osteosarcoma Cell Migration and Invasion by Targeting Runx2
}

\author{
Yuanlong Xie, Wenchao Sun, Zhouming Deng, Xiaobin Zhu, Chao Hu \& Lin Cai
}

Osteosarcoma patients with lung metastasis and local invasion remain challenging to treat despite the significant contribution of the combination of surgery and neo-adjuvant chemotherapy. Our previous microarray study demonstrated that miR-302b had significantly lower expression in osteosarcoma cell lines than in osteoblast cell lines. In the present study, we further elucidated the role of miR-302b in regulating the migration and invasiveness of osteosarcoma. MiR-302b expression was markedly down-regulated in osteosarcoma cell lines and clinical tumour tissues. Lower levels of miR-302b expression were significantly associated with metastasis and high pathological grades. A functional study demonstrated that over-expression of miR-302b suppressed tumour cell proliferation, invasion and migration in vitro and in vivo. Runx2 was identified as a direct target gene for miR-302b by bioinformatics analysis and dual-luciferase reporter gene assay. Moreover, over-expression of miR$302 \mathrm{~b}$ induced down-regulation of Runx2, OPN, MMP-2, MMP-9, MMP-12, MMP-14, and VEGF in 143B cells. Exogenous expression of Runx2 partially rescued the inhibitory effect of miR-302b on the invasion and migration activity of 143B osteosarcoma cells. Taken together, our results indicate that miR-302b functions as a tumour repressor in the invasion and migration of osteosarcoma by directly downregulating Runx2 expression and may be a potential therapeutic target for osteosarcoma.

Osteosarcoma arising from bone is the most common primary malignant tumour in children, adolescents, and young adults ${ }^{1}$. Despite the significant contribution of the combination of surgery and neo-adjuvant chemotherapy, the clinical outcomes and prognosis of patients suffering from osteosarcoma have made little progress in the past ten years ${ }^{2}$. Metastasis is one of the most intricate aspects of osteosarcoma. Osteosarcoma patients with lung metastasis mostly became unable to undergo surgery, leading to a 5 -year survival rate of under $30 \%{ }^{3}$. In contrast, the 5 -year survival rate of patients without distant metastasis is over $60 \%{ }^{4}$. The underlying molecular mechanisms of carcinogenesis and metastatic development remain unclarified. Accumulating evidence has shown that short non-coding RNA known as microRNAs (miRNAs) are involved in the progression and metastasis of osteosarcoma by regulating target mRNAs via binding to their $3^{\prime}$-untranslated regions (UTRs) in a sequence-specific pattern $^{5,6}$. MiRNAs dysfunction play significant roles in several biological processes, including cell proliferation, differentiation, apoptosis, cell cycle, migration and invasion ${ }^{7}$. For example, reduction of miR-143 increases osteosarcoma cell invasion by targeting MMP- $13^{8}$. In addition, miR-20a promotes the metastatic potential of osteosarcoma cells by regulating the Fas/FasL system ${ }^{9}$.

Our previous study demonstrated by miRNA microarrays and bioinformatic analysis that several miRNAs are differentially expressed between osteosarcoma and osteoblast cell lines ${ }^{10}$. MiR-302b, one of the 268 dysregulated miRNAs, is significantly under-expressed in osteosarcoma cell lines compared with osteoblast cell lines ${ }^{10}$. Furthermore, miR-302b can restrain the proliferation of osteosarcoma cells; promote cell apoptosis by regulating Akt/pAkt, Bcl-2, and Bim; and promote cell cycle arrest by attenuating the levels of cyclin D1 and CDKs ${ }^{11}$. In addition, evidence shows that miR-302b suppresses cell invasion and metastasis by directly targeting AKT2 in human hepatocellular carcinoma cells ${ }^{12}$. However, the potential function of miR-302b in osteosarcoma metastasis remains obscure.

In the current study, we explored the potential function of miR-302b in osteosarcoma cell invasion and migration. First, we examined the expression of miR-302b in osteosarcoma tissue and the relationship between $\mathrm{miR}-302 \mathrm{~b}$ and clinical characteristics of osteosarcoma patients. Moreover, we investigated the potential role of miR-302b in the cell proliferation, invasion, and migration of osteosarcoma cell lines. Next, we explored the 
A

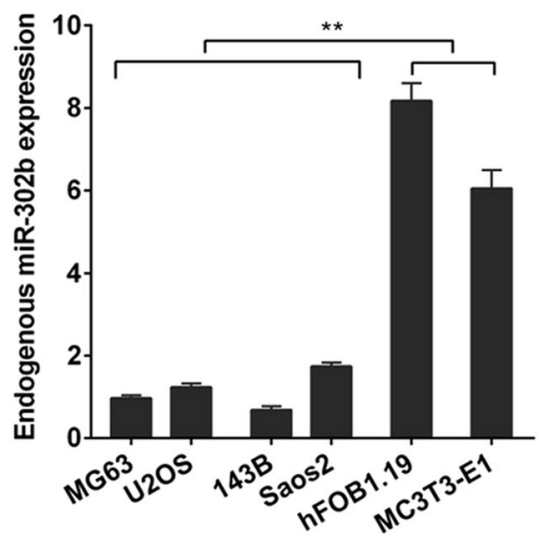

B

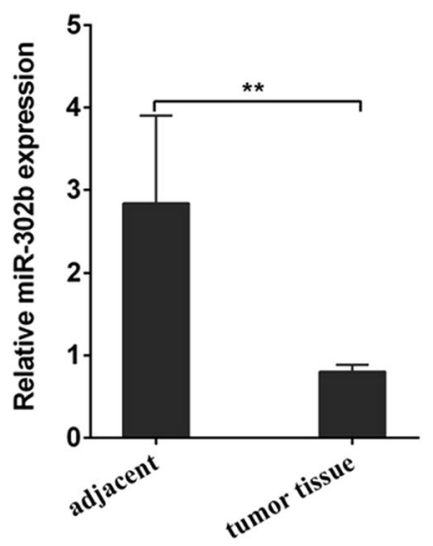

Figure 1. Dysregulated miR-302b in osteosarcoma tissues and cells. (A) qRT-PCR was used to analyse miR302b expression in osteosarcoma cells and osteoblastic cells. (B) qRT-PCR was performed to examine miR-302b expression in 31 pairs of tissue samples consisting of human osteosarcoma and adjacent normal bone tissues. $(* P<0.05, * * P<0.01)$.

\begin{tabular}{|c|c|c|c|c|}
\hline \multirow[b]{2}{*}{ Clinical feature } & \multicolumn{4}{|c|}{ miR-302b expression } \\
\hline & high $(\stackrel{a}{>}>0.81)$ & low $(\leq 0.81)$ & $t / X^{2}$ & $P$ \\
\hline Age (years) & $18.80 \pm 0.83$ & $16.94 \pm 0.99$ & 1.437 & 0.162 \\
\hline \multicolumn{5}{|l|}{ Gender } \\
\hline Male & 10 & 8 & 0.267 & 0.605 \\
\hline Female & 6 & 7 & & \\
\hline \multicolumn{5}{|l|}{ Primary site } \\
\hline Femur & 6 & 5 & 0.535 & 0.911 \\
\hline Tibia & 5 & 5 & & \\
\hline Humerus & 2 & 1 & & \\
\hline Other & 3 & 4 & & \\
\hline \multicolumn{5}{|l|}{ Metastasis } \\
\hline Yes & 9 & 13 & 4.454 & 0.035 \\
\hline No & 7 & 2 & & \\
\hline \multicolumn{5}{|l|}{ TNM grade } \\
\hline high grade & 8 & 14 & 5.444 & 0.020 \\
\hline low grade & 8 & 1 & & \\
\hline
\end{tabular}

Table 1. Correlation between the expression of miR-302b and clinicopathological data.

underlying molecular mechanism of the function of miR-302b in osteosarcoma by bioinformatics analysis and rescue experiments. Finally, the potential role of miR-302b in osteosarcoma was further demonstrated in a nude mouse model. The present study provided a deeper understanding of miR-302b in the development and progression of osteosarcoma.

\section{Results}

The relationship between miR-302b and clinical characteristics of osteosarcoma patients. Initially, quantitative real-time PCR (qRT-PCR) was used to detect the miR-302b expression levels of several osteosarcoma cell lines (MG-63,U2OS,143B,Saos2) and two osteoblastic cell lines (hFOB1.19, MC3T3-E1). The results showed that miR-302b expression levels in the MG-63,U2OS,143B, and Saos2 cell lines were significantly lower than those in the two osteoblastic cell lines (hFOB1.19, MC3T3-E1) (Fig. 1A).Then, detection of miR-302b expression was performed using qRT-PCR in 31 pairs of human primary osteosarcoma tumours and adjacent normal bone tissues. The results showed that the mean level of miR-302b was lower in osteosarcoma tissue than that in the adjacent normal bone tissues (Fig. 1B). To explore the clinicopathologic significance of miR-302b variation, we quantified the levels of miR-302b in 31 pairs of osteosarcoma tumours using qRT-PCR. A low-expression ( $\leq$ median) group and a high-expression ( $>$ median) group were defined using the median value $(0.81)$ of miR-302 b expression as a cut-off point. As shown in Table 1, low expression of miR-302b was significantly correlated with metastasis and high pathological grades $(\mathrm{P}<0.05)$, whereas no significant correlation was observed for other parameters. These results showed that downregulation of miR-302b contributed to OS pathogenesis. 
Overexpression of miR-302b suppresses cell proliferation of $143 \mathrm{~B}$ and MG-63 cells. To explore the potential role of miR-302b in osteosarcoma, we transiently transfected MG-63 and 143B osteosarcoma cells with miR-302b mimics and verified the miR-302b expression by qRT-PCR (Fig. 2A,B). Data from a CCK-8 assay showed that over-expression of miR-302b significantly suppressed the proliferation of 143B and MG-63 cells (Fig. 2C,D). Apoptosis and cell cycle distribution were examined to determine whether they accompanied the observed inhibition of cell growth. Over-expression of miR-302b increased cell apoptosis both in 143B cells and in MG-63 cells (Fig. 2E,F). As shown in Fig. 2G,H, the percentages of 143B and MG-63 osteosarcoma cells in G0/ $\mathrm{G} 1$ significantly increased after the miR-302b transfection $(\mathrm{P}<0.05)$. Our results suggested that miR-302b could induce cell apoptosis and cell cycle arrest, which might contribute to the inhibition of cell proliferation.

Overexpression of miR-302b suppresses migration and invasion of 143B and MG-63 cells. Further investigation was conducted on whether miR-302b inhibits the migration and invasion capabilities of osteosarcoma. The data from the wound healing assay showed that over-expression of miR-302b significantly suppressed the migration of $143 \mathrm{~B}$ and MG-63 cells (Fig. 3A,B). The distance of cell migration was calculated to quantitatively determine the migration ability of the cells (Fig. 3C). Consistently, over-expression of miR-302b suppressed cell invasion of 143B and MG-63, which was determined using transwell assays (Fig. 3D,E,F).

miR-302b targets the Runx2 gene in 143B cells. Potential target genes were predicted by three online bioinformatics analysis software programs including miRWalk, miRbase and Target Scan. Runx 2 containing a miR-302b binding site in the $3^{\prime}$-UTR was uniformly predicted by the software and Runx 2 was selected for further experiments. A dual-luciferase reporter system containing a wild-type (AGCACUU) or mutant (GAUGAGC) 3'-UTR of Runx2 was used to verify whether miR-302b directly interacts with the $3^{\prime}$-UTR of Runx2 (Fig. 4A). 143B cells were co-transfected with miR-302b or miR-ctrl and with pmirGLO- Runx2-3'-UTR-wt or pmirGLO-Runx2-3'-UTR-mut. The data showed that the transfection with miR-302b significantly suppressed the luciferase activity of pmirGLO-Runx2-3'-UTR-wt but did not affect the luciferase activity of the pmirGLO reporter carrying the mutant Runx2-3'-UTR (Fig. 4B).MG-63 and 143B osteosarcoma cells were transiently transfected with miR-302b inhibitors and the down-regulation of miR-302b was verified by qRT-PCR (Fig. 4C). qRT-PCR and Western blotting were performed to detect the levels of mRNA and protein, respectively. Compared with the negative control group, the protein levels of Runx2 were significantly reduced or promoted in response to miR-302b mimics and miR-302b inhibitors, respectively, in 143B and MG63 cells (Fig. 4D). Additionally, the mRNA levels of Runx 2 were significantly reduced or promoted respectively in response to miR-302b mimics and miR-302b inhibitors compared with the negative control group in 143B and MG63 cells (Fig. 4E,F). qRT-PCR was used exploring the expression levels of Runx2 in OS cells (MG-63,U2OS,143B,Saos2) relative to osteoblast cells (hFOB1.19) and 31 pairs OS tissue relative to adjacent tissue. The results showed that Runx 2 mRNA expression levels in several osteosarcoma cell lines were significantly lower than those in the two osteoblastic cell lines (Fig. 4G). The mean expression level of Runx2 mRNA was lower in osteosarcoma tissue than in the adjacent normal bone tissues (Fig. 4H). These results indicated that the Runx2-3'-UTR carried the binding sites for miR-302b.

MiR-302b and the target gene Runx2 share analogous molecular effects in 143B osteosarcoma cells. Runx2 expression was silenced by RNAi method to detect whether Runx2 was involved in the anti-tumour effect of miR-302b. First, the transfection rate of Runx2 over-expression vector, Runx2-siRNA were verified by qRT-PCR in 143B cells (Fig. 5A). As shown in Fig. 5B-D, miR-302b mimics suppressed the mRNA and protein levels of Runx2, OPN, MMP-2, MMP-9, MMP-13, MMP-14 and VEGF compared with the negative control group in 143B cells. In addition, an miR-302b inhibitor promoted the mRNA and protein levels of these gene products, which are the essential regulators of cell migration and invasion. Notably, Runx2 siRNA could inhibit the mRNA and protein level of Runx2, OPN, MMP-2, MMP-9, MMP-13, MMP-14 and VEGF, similar to the suppressive effect mediated by miR-302b mimics in 143B cells. These data suggested that miR-302b and the target gene Runx2 share analogous molecular effects in 143B osteosarcoma cells.

Overexpression of Runx 2 rescues the inhibitory effect of miR-302b on $143 B$ cells. To further demonstrate the tumour suppressor function of miR-302b through targeting of Runx2, an miR-302b mimic (miR-302b) or miR-ctrl and a Runx2 over-expression vector (Runx2) or a negative control vector (Runx2-ctrl) were co-transfected into 143B cells. As shown in Fig. 6A-D, cell invasion and migration were up-regulated after the co-transfection of miR-302b and Runx 2 compared with the co-transfection of miR-302b and Runx2-ctrl. In other words, over-expression of Runx 2 counterbalanced the tumour suppressor effect of miR-302b mimics on cell invasion and migration in 143B cells. As shown in Fig. 6E,F, over-expression of Runx2 in 143B cells rescued the down-regulation of Runx 2 protein expression level mediated by miR-302b mimics. Furthermore, the results showed that over-expression of Runx 2 in 143B cells also rescued the miR-302b mimics mediated down-regulation of protein expression of OPN, MMP-2, and MMP-9. These results revealed that over-expression of Runx2 rescued the inhibitory effect of miR-302b on 143B osteosarcoma cells, which further demonstrated that miR-302b suppressed the 143B osteosarcoma cells by targeting Runx 2 .

miR-302b inhibits orthotopic osteosarcoma tumour growth and lung metastasis in nude mice. To explore the effect of miR-302b on tumourigenicity in vivo, we conducted orthotopic tumour transplantation by injecting $143 \mathrm{~B}$ cells into the tibia periosteum of nude mice. Seven days later, a miR-302b agomir was injected intratumourally, and the animals were monitored closely for tumour growth for 3 weeks. The success of the orthotopic tumour was determined by X-ray images in which bone destruction, periosteal reaction and soft tissue mass could be assessed (Fig. 7A,B,C). As shown in Fig. 7C,D, treatment with miR-302b agomir resulted in a reduction of more than $40 \%$ in tumour volume compared with the control group. The mice were anaesthetized, and their 
A

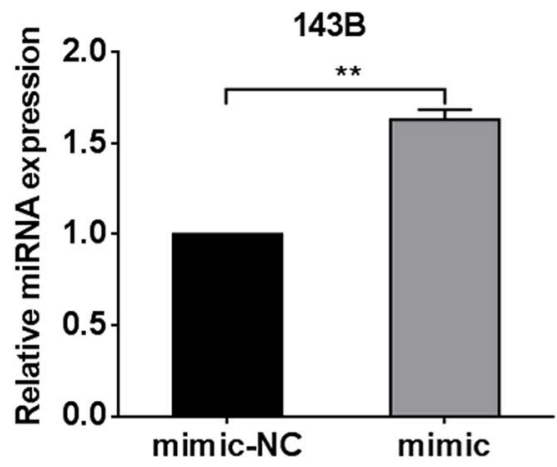

MG63

C

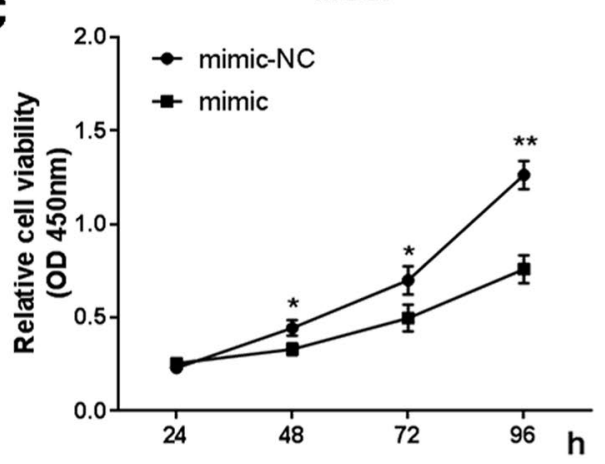

E

143B mimic-NC mimic

뽀

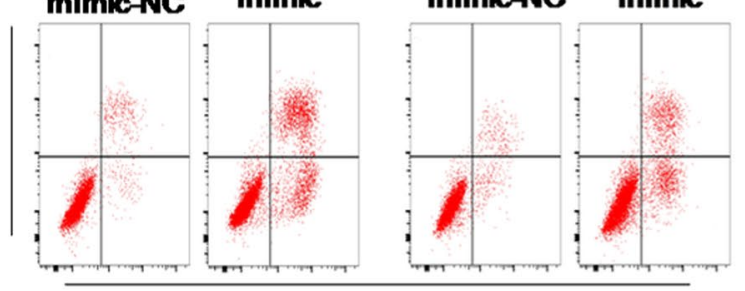

FITC

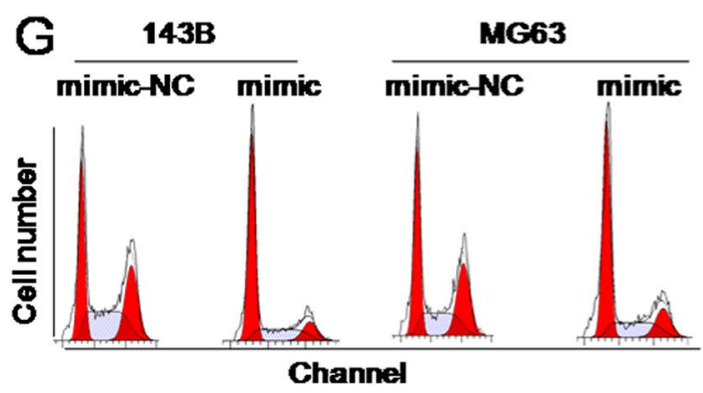

B

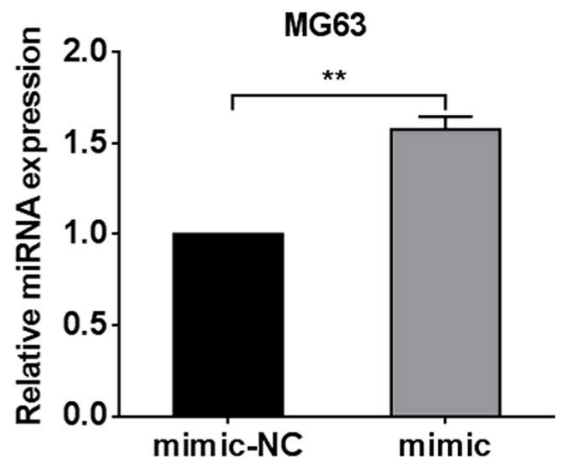

143B

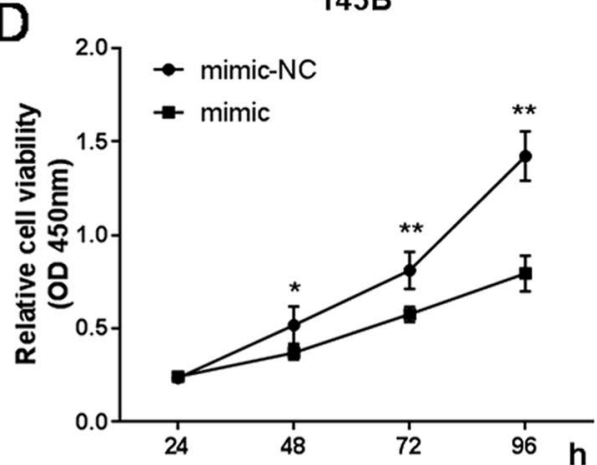

F

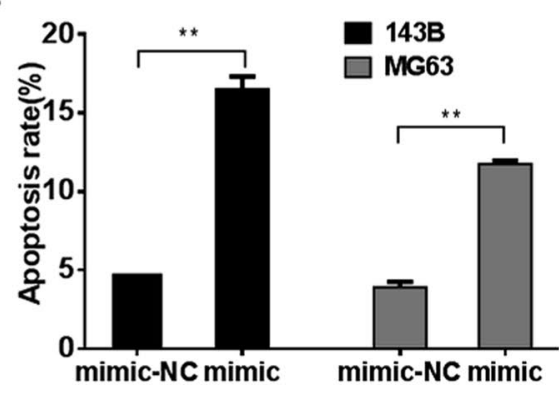

$\mathrm{H}$

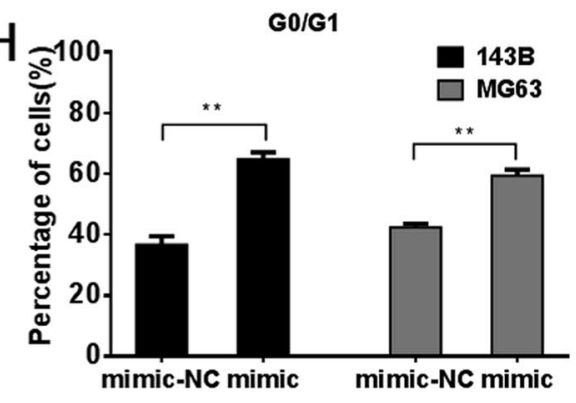

Figure 2. miR-302b suppresses the proliferation and induces cell apoptosis and cycle arrest of 143B/MG-63 cells. (A and B) qRT-PCR analysis of miR-302b in 143B, MG63 cells transfected with miR-302b mimic (mimic), or miR-302b negative control (mimic-NC) as a control. (C) The effect of miR-302b mimics on $143 \mathrm{~B}$ cell proliferation was detected with CCK- 8 assays at $24,48,72$, and 96 hours. (D) The effect of miR-302b mimics on MG-63 cell proliferation was detected with CCK-8 assays at 24, 48, 72, and 96 hours. (E,F) 143B/MG63 cells were transfected with miR-302b mimic, or mimic-NC as control. The cell apoptosis profiles were detected using flow cytometry. (E) A representative image of FACS plot. The FACS plot shows the cells in early (bottom right quadrant) and late apoptotic states (upper right quadrant). Viable cells are double negative (bottom left quadrant). (F) The results of a quantitative analysis. (G and H) 143B/MG63 cells were transfected with miR-302b mimic, or mimic-NC as control. The cell cycle profiles were detected using flow cytometry. (G) A representative image. $(\mathbf{H})$ The results of a quantitative analysis. The results are expressed as the means $\pm \mathrm{SD}$ of three independent experiments (NC: negative control, $* P<0.05, * * P<0.01$ ). 
A

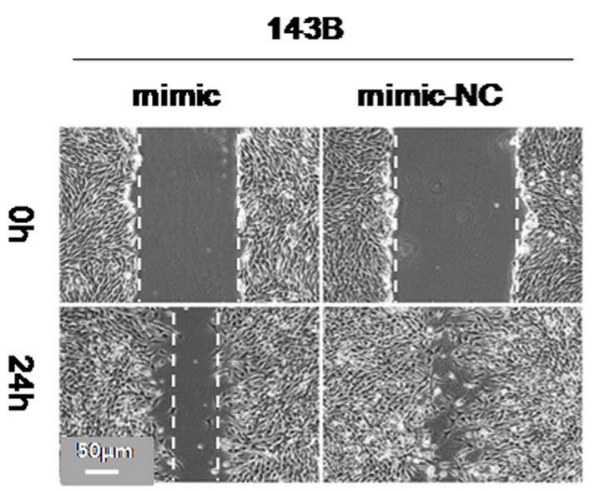

\section{C}

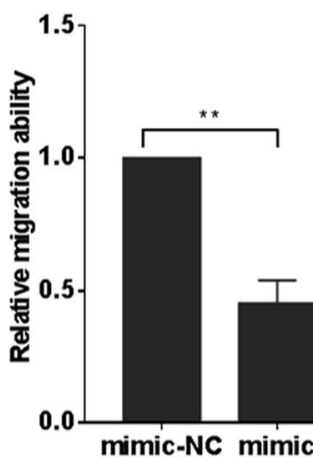

Migration

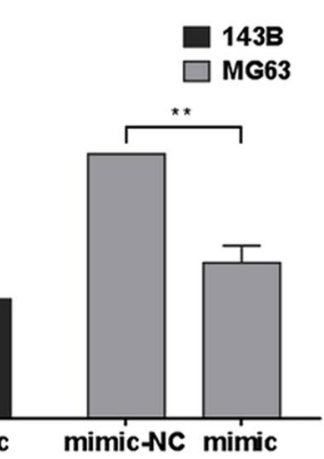

$E$

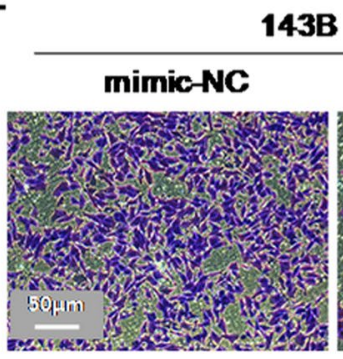

B

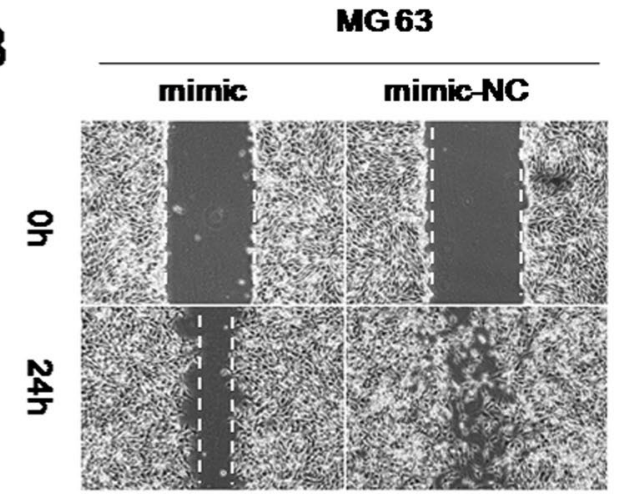

D
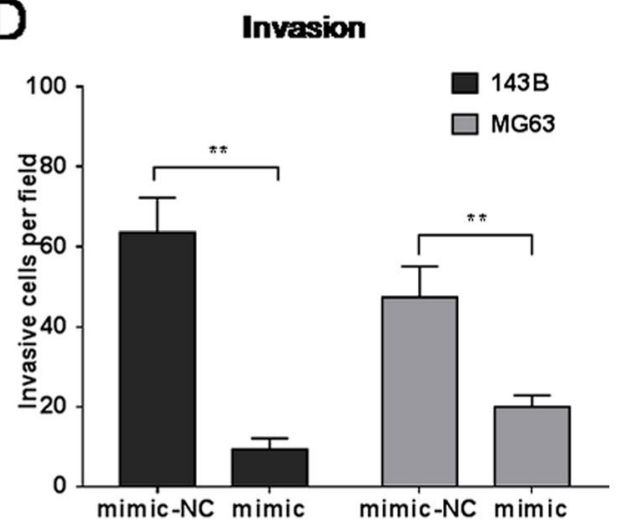

$\mathrm{F}$ MG63

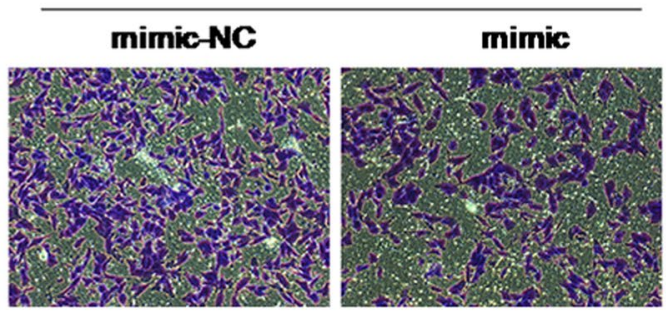

Figure 3. miR-302b suppresses the migration and invasion activity of $143 \mathrm{~B} / \mathrm{MG}-63$ cells. (A and B) The effects of miR-302b mimics on the invasion ability of $143 \mathrm{~B}$ and MG-63 cells were determined by a wound healing assay. (C) Relative migration ability was measured by the equation described in Materials and Methods. (D) Number of invasive cells was counted under a microscope in each group. (E and F) Representative results of a transwell assay detecting the effect of miR-302b mimics on $143 \mathrm{~B}$ and MG-63 cells. (NC: negative control, $* P<0.05$, $* * P<0.01)$.

tumours and lungs were dissected and stained with $\mathrm{H} \& \mathrm{E}$ to evaluate tissue morphology. H\&E staining results of tumour tissue in the miR-302b agomir-treated group showed a larger area of necrosis than was found in the control group (Fig. 7E). These results suggested that miR-302b- agomir inhibited osteosarcoma tumour growth in vivo. Compared with the control group, the number of lung metastasis nodules was significantly reduced in the miR-302b agomir treatment group, as evidenced by $\mathrm{H} \& \mathrm{E}$ staining and macroscopic observation of lung specimens (Fig. 7F,G,H).

\section{Discussion}

Dysregulation of miRNAs has been thoroughly documented in almost all types of human malignancy ${ }^{13,14}$. Improved investigation on the gene interaction mediated by miRNAs may provide further potential biomarkers and therapeutic targets for patients suffering from cancer. In the current study, preliminary evidence was presented about the negative regulatory role of $\mathrm{miR}-302 \mathrm{~b}$ in osteosarcoma invasion and migration via targeting Runx2.

MiR-302b is differentially expressed in several human cancers. Specifically, miR-302b is down-regulated in breast cancer ${ }^{15}$, hepatocellular carcinoma ${ }^{16}$, pleural mesothelioma ${ }^{17}$, and gastric cancer ${ }^{18}$ and acts as a tumour-suppressing, anti-oncogenic miRNA. Our results revealed that miR-302b expression level was lower in 
A

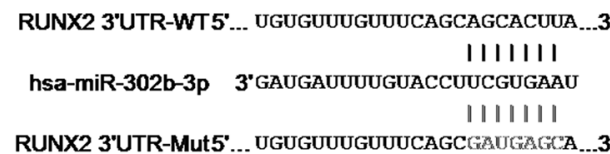

B

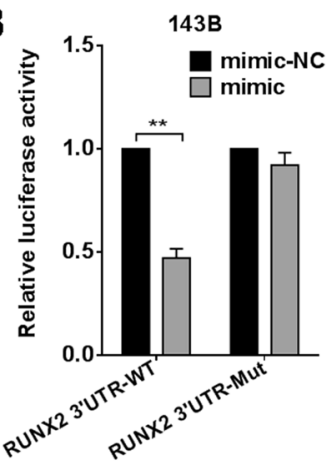

E

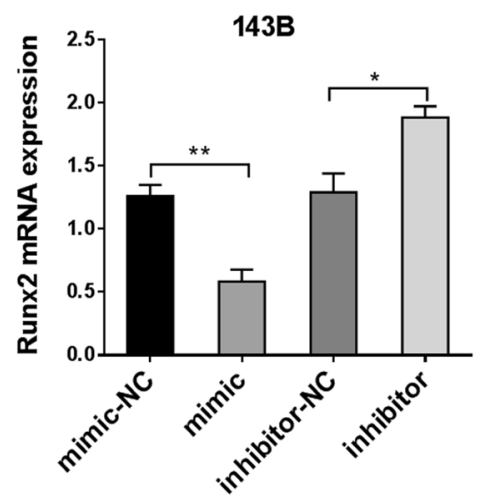

G

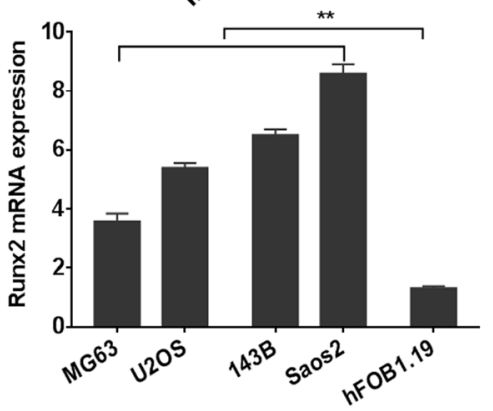

D

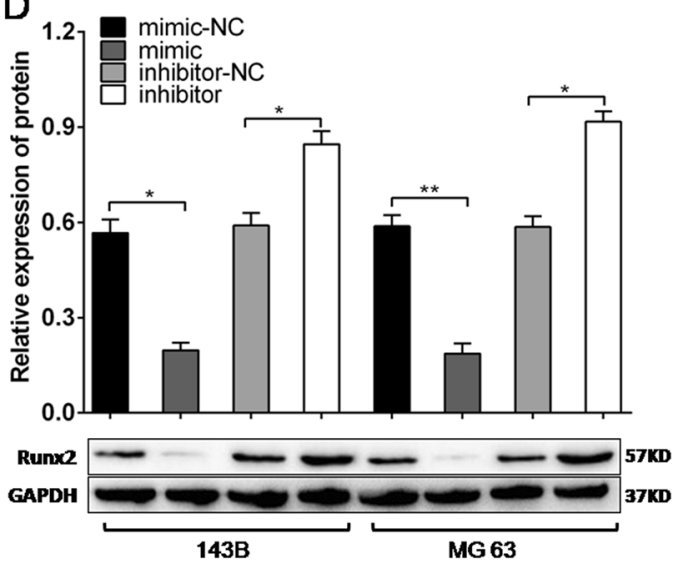

$\mathrm{F}$

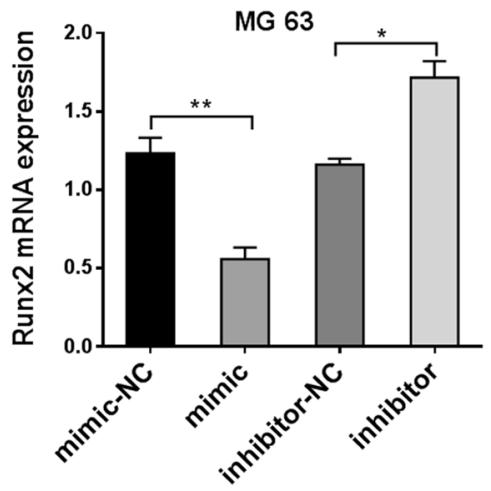

$\mathrm{H}$

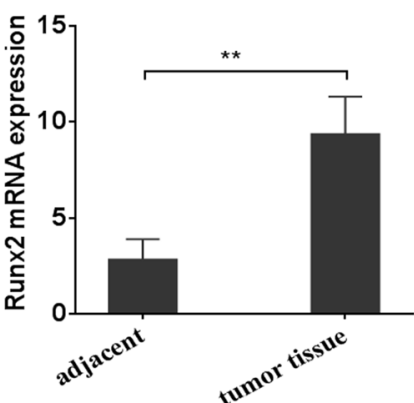

Figure 4. miR-302b targets the Runx 2 gene. (A) Binding sites of miR-302b in the $3^{\prime}$-UTR region of Runx2. A mutant miR-302b binding site was generated in the complementary site for the seed region of miR-302b. (B) pmirGLO-Runx2-3'-UTR-wt or pmirGLO-Runx2-3'-UTR-mut was co-transfected with miR-302b or miR-ctrl in 143B cells, and the relative luciferase activity was measured. (C) qRT-PCR analysis of miR-302b in 143B, MG63 cells transfected with miR-302b inhibitor, or inhibitor-NC as a control. (D) Detection of Runx2 proteins in 143B and MG-63 cells after transfection with miR-302b mimics/inhibitor. (E and F) Detection of Runx2 mRNA in 143B and MG-63 cells after transfection with miR-302b mimics/inhibitor. (G) Detection of Runx2 mRNA in several osteosarcoma cells and osteoblast cell lines. (H) Detection of Runx2 mRNA in 31 pairs of osteosarcoma tissues and adjacent tissues. (NC: negative control, ${ }^{*} P<0.05,{ }^{* *} P<0.01$ ).

osteosarcoma cell lines than in osteoblastic cell lines. Consistent with our previously published microarray data ${ }^{10}$, miR-302b was significantly down-regulated in osteosarcoma tissues compared with the normal adjacent bone tissues in the present study. Low expression of miR-302b was associated with distant and lymph node metastasis in osteosarcoma. Furthermore, from a gain-of-function study, miR-302b dramatically induced apoptosis and cell cycle arrest and suppressed cell proliferation, invasion, and migration in vitro. Likewise, treatment with miR$302 \mathrm{~b}$ agomir significantly reduced the proliferation and lung metastasis of osteosarcoma in vivo. Therefore, our results presented a more comprehensive understanding of the potential tumour suppressor role of miR-302b in osteosarcoma progression.

Local invasion and metastasis are the main causes of death in osteosarcoma patients ${ }^{8}$. Therefore, it is essential to determine the mechanisms governing the metastasis of osteosarcoma to develop novel therapeutic strategies 
A

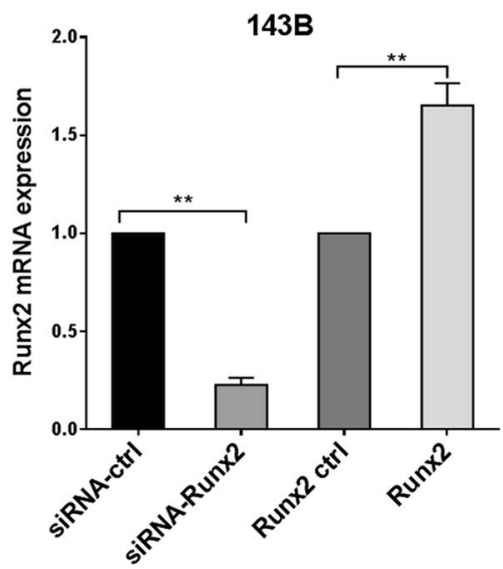

B

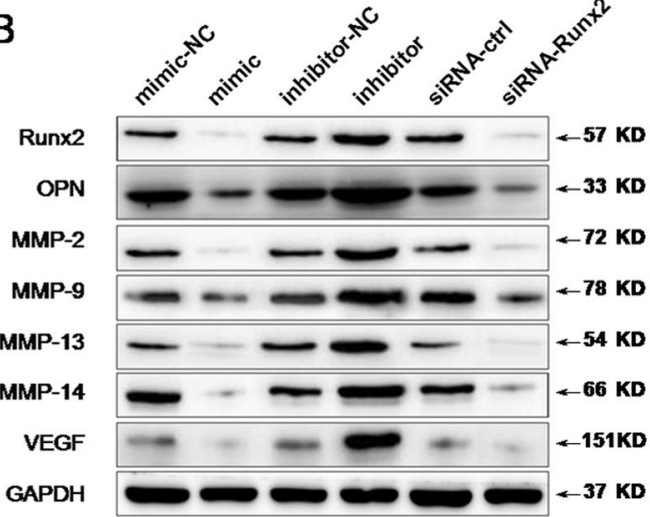

C

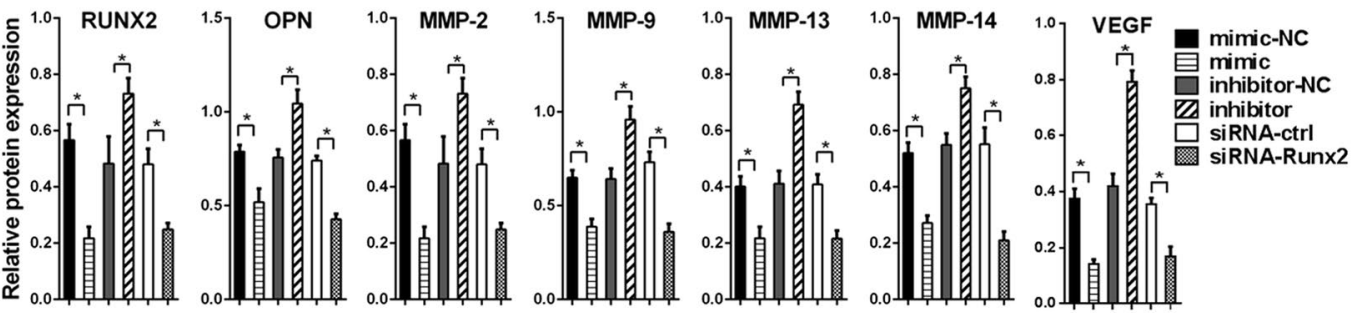

D

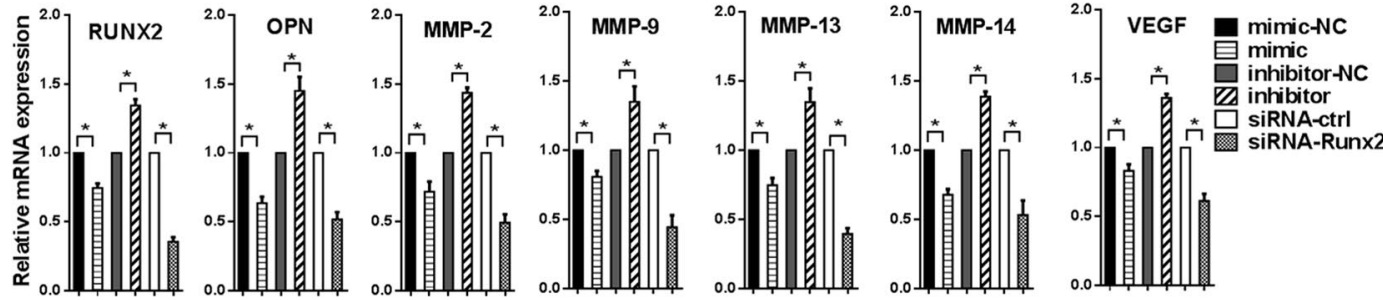

Figure 5. miR-302b and the target gene Runx2 share analogous molecular effects in 143B osteosarcoma cells. (A) qRT-PCR analysis of Runx2 in 143B cells transfected with siRNA-Runx2 or a Runx2 overexpression construct, with an siRNA control and an empty vector, respectively, as their controls. (B) Detection of Runx2, OPN, MMP-2, MMP-9, MMP-13, MMP-14 and VEGF proteins in 143B cells after transfection with miR-302b mimics/inhibitor or siRNA-Runx2. (C) Relative protein expression level in each group. (D) Detection of Runx2, OPN, MMP-2, MMP-9, MMP-13, MMP-14 and VEGF mRNA in 143B cells after transfection with miR-302b mimics/inhibitor or siRNA-Runx2. $(* P<0.05, * * P<0.01)$.

for osteosarcoma patients. In general, miRNAs fulfil their biological function via regulating their target genes. Several target genes of miR-302b have been identified, including E2F1 ${ }^{15}, \mathrm{E} 2 \mathrm{~F} 3^{19}, \mathrm{Mcl}-1^{20}, \mathrm{CDK} 2^{18}, \mathrm{AKT} 2^{16}$ and $\mathrm{ErbB}^{21}$. Based on bioinformatics analysis, Runx 2 was further identified as a putative target gene of miR-302b and that was verified by luciferase reporter assays in present study. Additionally, in miR-302b-overexpressing and miR-302b-downregulated osteosarcoma cells, the mRNA and protein levels of Runx2 were inhibited and promoted, respectively.

Runx2, belonging to the Runt domain family of transcription factors, is required for the differentiation of mesenchymal cellsalong the osteoblast lineage ${ }^{22,23}$. Sadikovic et al. ${ }^{24}$ reported that RUNX2 was significantly overexpressed in human osteosarcoma tumours and osteosarcoma cell lines compared with their counterparts. In addition, Runx 2 is critical for osteosarcoma metastasis. Reduced Runx 2 protein expression has been directly linked to upregulated miRNAs in human osteosarcoma cells compared with mesenchymal progenitor cells ${ }^{25}$. These genetic studies suggest that Runx2 may play a critical role in osteosarcoma oncogenesis on account of its significant function in regulating osteoblast differentiation and cell invasion and migration. Indeed, several miRNAs have been identified to directly target Runx2 mRNA to generate their biological effects. For example, Qin et al. showed that miR-455 restrains the cell migration and invasion activity of human hepatocellular carcinoma by targeting Runx $2^{26}$. Consistently, miR-217 represses cell proliferation and invasion by targeting Runx 2 in human glioma ${ }^{27}$. Furthermore, in osteosarcoma, Runx2 is also targeted by several miRNAs including miR-34c $\mathrm{c}^{28}$, 

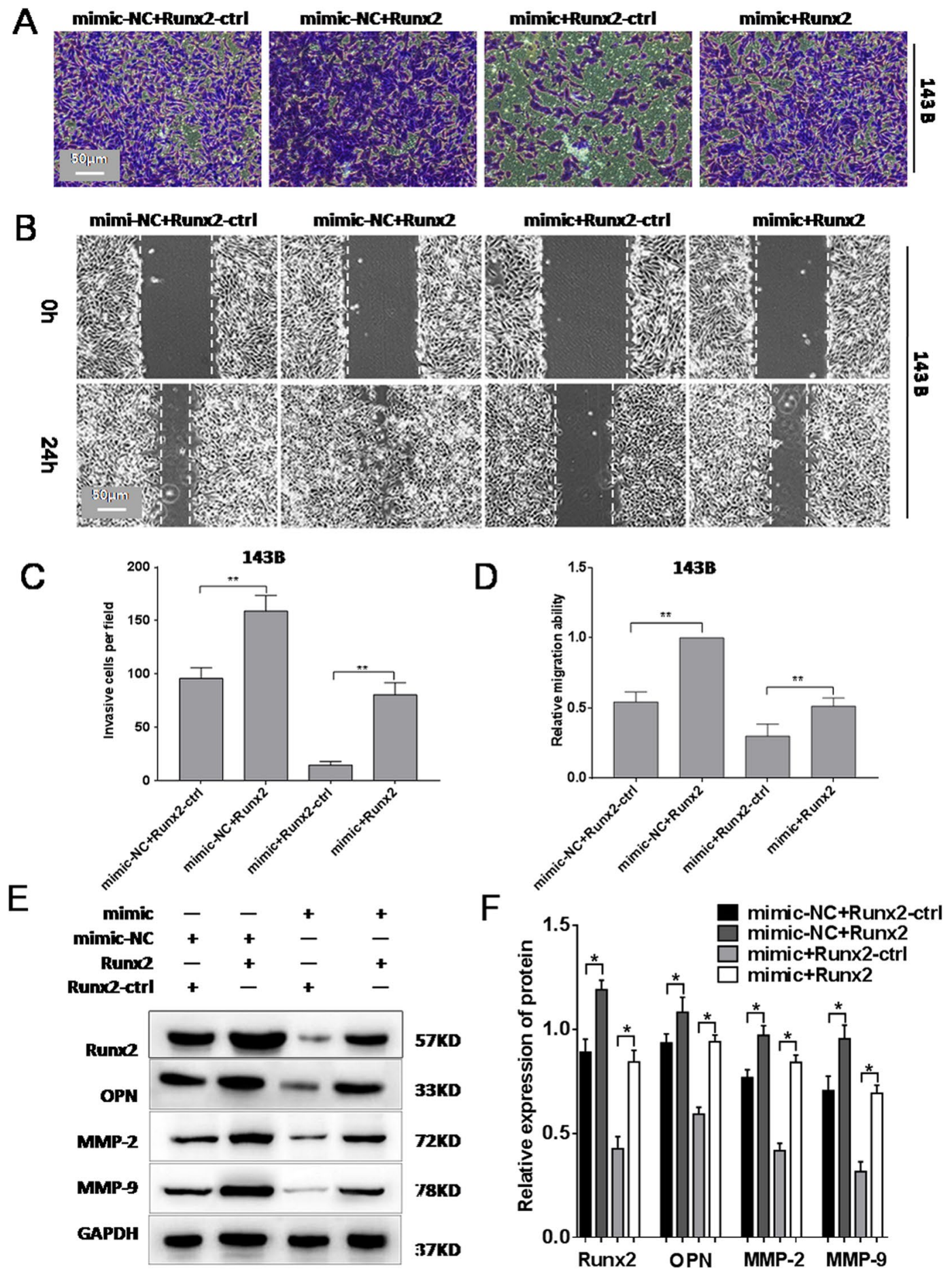

Figure 6. Overexpression of Runx2 rescued the inhibiting effect of miR-302b on 143B osteosarcoma cells. (A) miR-302b mimic (miR-302b) or miR-302b negative control (miR-ctrl) and Runx2 overexpression construct (Runx2) or an empty vector (Runx2-ctrl) were cotransfected into 143B/MG-63 cells, and the representative results of the transwell assay were shown. (B) Representative results of a wound healing assay in 143B cells. (C) number of invasive cells counted under a microscope in each group. (D) Relative migration ability of each group. (E) Detection of Runx2, OPN, MMP-2, and MMP-9 proteins in 143B after the transfection. (F) Relative protein expression level in each group. $(* P<0.05, * * P<0.01)$.

miR-205 29 , miR-30a ${ }^{30}$, miR-23a ${ }^{31}$. Our data indicate for the first time that Runx2 is a functional target of miR302b. Down-regulation of Runx 2 resulted in significant repression of cell invasion and migration, mimicking the biological effect of miR-302b overexpression. Moreover, upregulation of Runx2 significantly rescued the repressive effect of miR-302b. 
A

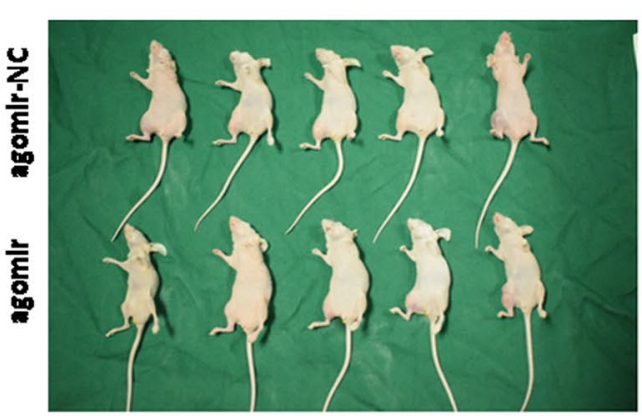

C

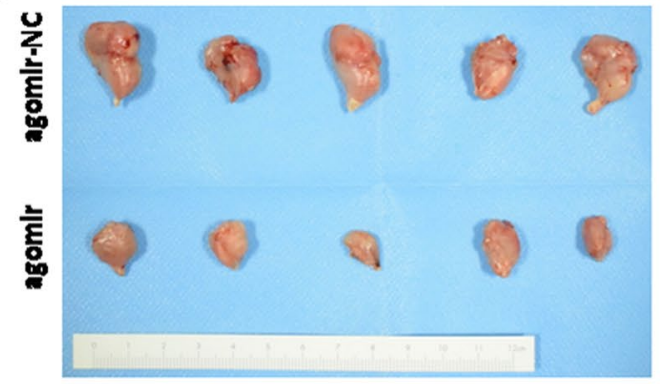

E

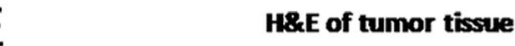

B

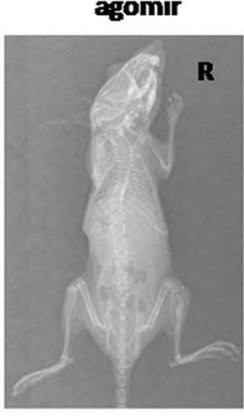

D

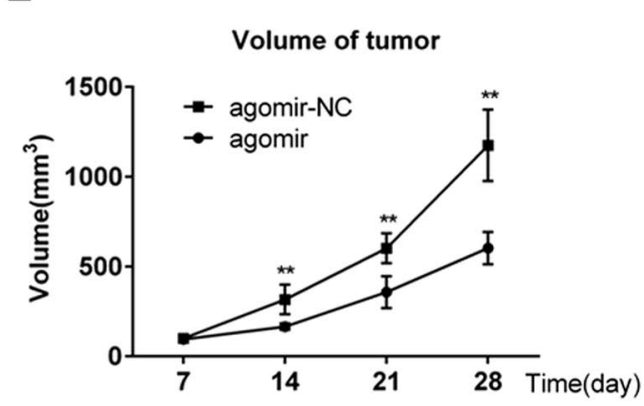

$\mathrm{F}$

agomir-NC

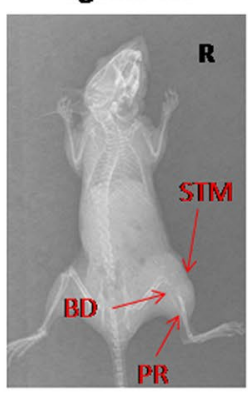

T1/4

Metastatic lung nodules

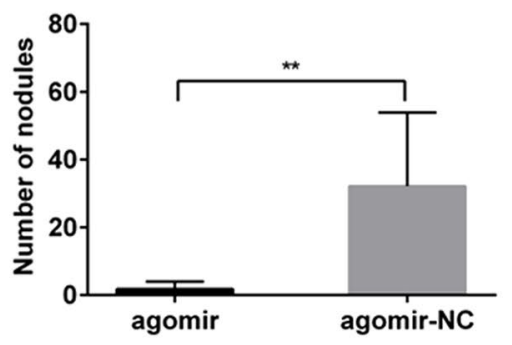

G

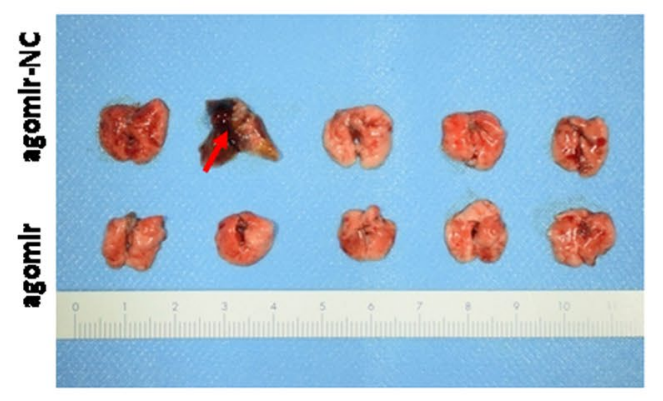

$\mathrm{H}$

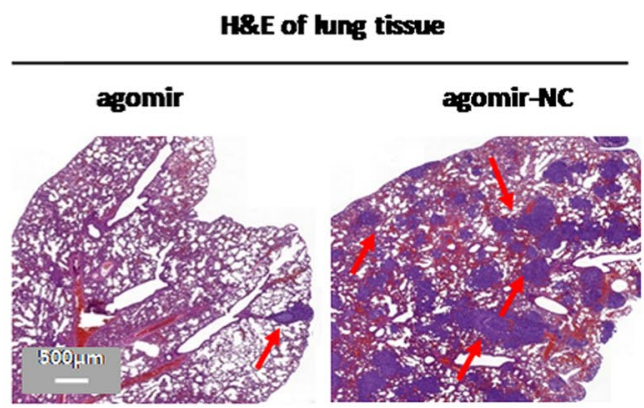

Figure 7. MiR-302b inhibited osteosarcoma tumour growth and lung metastasis in nude mice. (A) Orthotopic tumour transplantation was conducted by injecting $143 \mathrm{~B}$ cells into the tibial periosteum of nude mice $(n=5)$. At three weeks after treatment with miR-302b agomir (agomir) or agomir negative control (agomir-NC), mice were sacrificed. (B) Orthotopic tumours were identified by X-ray imaging in which bone destruction (BD), periosteal reaction (PR) and soft tissue mass (STM) could be found. (C) Representative tumours are shown. (D) Representative photos of H\&E-stained sections of orthotopic tumours formed in the two groups. (E) Growth curve of tumour volumes. (F) Quantification of lung metastatic nodules in each group. (G) Representative photos of lung tissue isolated from sacrificed mice in each group. $(\mathbf{H})$ Representative photos of H\&E-stained sections of lung tissue from each group and arrows represent the metastatic nodules. $(* P<0.05, * * P<0.01)$.

Taken together, our results show that decreased miR-302b expression in osteosarcoma is associated with tumour development and metastasis. Furthermore, miR-302b functions as a tumour repressor in the invasion and migration activity of osteosarcoma by downregulating Runx2. Accordingly, deeper clarification of the specific role of miR-302b is proposed in the interest of identifying a potential therapeutic target for osteosarcoma. 


\section{Materials and Methods}

Cell lines and tissue specimens. The human osteosarcoma cell lines MG-63 and 143B, purchased from the China Centre for Type Culture Collection (Wuhan, China), were maintained in DMEM (Gibco, Shanghai,China) containing 10\% FBS (Gibco, Scoresby, Australia) and 1\% antibiotics (penicillin and streptomycin). Thirty-one pairs of osteosarcoma and adjacent noncancer bone tissue samples were collected from patients undergoing biopsy before the chemotherapy at the orthopaedics department of Zhongnan Hospital of Wuhan University. Tissue specimens were immediately flash frozen in liquid nitrogen and stored until RNA extraction. The study was approved by the Institute Research Ethics Committee of Zhongnan Hospital of Wuhan University. Informed consent was obtained from all participants and/or their legal guardians. The human sample collection and treatment for total RNA isolation in present study were carried out in accordance with the approved guidelines.

Plasmids construction and transfection. MiR-302b minic (mimic), miR-302b inhibitor (inhibitor), miR-negative control, Runx2 expression vectors, siRNA-ctrl, and siRNA-Runx2 were purchased form Guangzhou Ribobio Co., LTD. Cells were transiently transfected with $50 \mathrm{nM}$ mimics or $50 \mathrm{nM}$ inhibitor using Lipofectamine 2000 (Invitrogen). After 24 hours of transfection, the transfection efficiency was verified by qRT-PCR and the subsequent experimental procedure was performed. Other transfections were also performed by using Lipofectamine 2000 according to the manufacturer's instructions.

Quantitative real-time PCR analysis. Total RNA was extracted from tumour specimens and sample cells using TRIzol (Invitrogen). cDNA was synthesized by reverse transcription from total RNA using a Prime Script RT Reagent Kit (Toyobo, Japan) following the manufacturer's introductions. Quantitative real-time PCR was performed using SYBR ${ }^{\circledR}$ Green qPCR Master Mix (Thermo Fisher Scientific). The gene expression of mature miR-302b was normalized to U6 as an endogenous control, and the expression of Runx2 was normalized relative to the endogenous control of human glyceraldehyde-3-phosphate dehydrogenase (GAPDH). The relative expression of these genes was calculated using the $2^{-} \Delta \Delta \mathrm{Ct}$ method $^{32}$. The specific primers were as follows: miR-302b forward 5'-ATCCAGTGCGTGTCGTG-3', reverse 5'-TGCTTAAGTGCTTCCATGTT-3'; U6 forward 5'-CTCGCTTCGGCAGCACATATACT- $3^{\prime}$, reverse $5^{\prime}$ - ACGCTTCACGAATTTGCGTGTC-3'; Runx2, forward 5'-TGACCAGTCTTACCCCTCCT-3', reverse 5'-CTGAAGCACCTGAAATGCG-3'; MMP2 forward 5'- AGATCTTCTTCTTCAA GGACCGGTT-3', reverse 5'-GGCTGGTCAGTGGCTTGGGGTA-3'; MMP9, forward 5' - CGCTGGGCTTAGATCATTCC $-3^{\prime}$, reverse $5^{\prime}$ - AGGTTGGATACATCACTGCATTAGG-3'; MMP-13, forward $5^{\prime}$ - CCTTCTGGTCTTCTGGCACAC-3' ${ }^{\prime}$, reverse $5^{\prime}$ - GGCTGGGTCACACTTCTCTGG-3'; MMP-14, forward 5' - AGCCCCGAAGCCTGGCTACA - $3^{\prime}$, reverse 5'-GCCGCCCTCACCATCGAAGG -3'; VEGF, forward 5' - AGGAGGAGGGCAGAATCATCA- $3^{\prime}$, reverse $5^{\prime}$ - CTCGATTGGATGGCAGTAGCT - $3^{\prime}$; GAPDH,forward 5'-TCCACCACCCTGTTGCTGTA-3' ${ }^{\prime}$, reverse 5' -ACCACAGTCCATGCCATCAC-3'.

CCK-8 assay. Cells were seeded in 96-well plates (Corning, USA) and cultivated for 24, 48, 72, or 96 hours after transfection. CCK-8 working solution was added to each well, followed by incubation at $37^{\circ} \mathrm{C}$ for 2 hours. Absorbance was measured at $450 \mathrm{~nm}$ with a Microplate Autoreader (SpectraMax M2, Molecular Devices, Sunnyvale, CA, USA). Experiments were repeated three times.

Apoptosis and cell cycle assay. For apoptosis detection, cells $\left(1 \times 10^{5}\right.$ cells per well $)$ were seeded in 6 -well plates. At 24 hours after transfection, the cells were stained with an AnnexinV/PI double staining kit (Biotyme) according to the manufacturer's instructions. Apoptotic cells were detected by flow cytometry. For cell cycle analysis, transfected cells were detached by trypsin digestion and washed with ice-cold PBS. Then, the cells were resuspended and fixed in $80 \%$ ethanol for at least 8 hours at $-20^{\circ} \mathrm{C}$. The cells were stained with $50 \mu \mathrm{g} / \mathrm{ml}$ propidium iodide (Keygen, Nanjing, China). Cell cycle distribution was analysed using a FACS Calibur (BD Bioscience, MA, USA).

Transwell assay. Cell invasion was evaluated using a transwell assay performed according to the manufacturer's instructions (BD, Biosciences). After 24 hours of transfection, cells were resuspended in serum- free medium. Then, cell suspension was added to the top chamber, which was coated in advance with $60 \mu$ lof Matrigel (dilution of 1:8), followed by incubation at $37^{\circ} \mathrm{C}$ in a humidified incubator for 12 hours. The lower chamber was filled with DMEM medium containing 10\% FBS. Cells that invaded through the transwell chamber were fixed with formaldehyde for $10 \mathrm{~min}$, washed with PBS, stained with crystal violet (Sigma-Aldrich). The invasion ability of the cells was quantitated by counting cells in five different areas under a microscope.

Wound healing assay. Cell migration ability was evaluated using a wound healing assay. Cells were seeded in 6 -well plates and allowed to reach $80 \%$ confluence. A wound was artificially created by scratching the cell monolayer with a $200 \mu$ l pipette tip. Plates was washed with PBS to remove the detached cells and maintained in Opti-MEM I Reduced-Serum Medium (Gibco). Wound closure was observed at 0 and 24 hours, and the image was photographed using a microscope. The migration distance (MD) in each group was calculated according to the following equation: $\mathrm{MD}=$ the width of the scratch at 0 hours $\left(W_{i d t h}{ }_{0 h}\right.$ - the width of the scratch at 24 hours $\left(\right.$ Width $\left._{24 \mathrm{~h}}\right)$. The MD of the control group was used as a reference. The relative cell migration ability was determined by the following equation: Relative cell migration ability $=\mathrm{MD}$ (experimental group)/MD (control group).

Dual-luciferase reporter gene assay. A Dual-Luciferase Reporter Assay System (Promega) was used to detect the luciferase reporter gene. All procedures were performed as previously described ${ }^{33}$. The $3^{\prime}$-UTR reporter plasmids were synthesized by placing amiR-302b seed sequence containing a Runx2 $3^{\prime}$-UTR fragment in the pmirGLO-REPORT Luciferase miRNA Target Expression Reporter Vector. The wild-type or mutant reporter 
vector was cotransfected into $143 \mathrm{~B}$ cells in 96 -well plates with $50 \mathrm{nmol} / \mathrm{L} \mathrm{miR-302b}$ or $50 \mathrm{nmol} / \mathrm{L} \mathrm{miR-NC}$ and pmirGLO plasmid via using Lipofectamine 2000. The reporter gene assays were conducted 24 hours after transfection using the Dual-Luciferase Reporter assay system following the manufacturer's protocol. The normalized luciferase activity for each construct was compared with that of the pmirGLO Vector control. All experiments were performed at least three times.

Western blot analysis. Sample cell and tissue specimens were lysed with RIPA solution containing protease inhibitor. The lysates, containing total protein, were centrifuged to remove the cellular debris. Protein concentrations were measured with the Bradford protein assay (Beyotime, China) following the protocol. Total protein samples were separated by $10 \%$ SDS-PAGE and transferred to a PVDF membrane (Millipore, Billerica, USA). The membrane was blocked using 5\% skim milk in TBST solution for 2 hours at room temperature. After triplicate washes in TBST, the membrane was incubated with specific primary antibodies against Runx2, OPN, MMP-2, MMP-9, MMP-13, MMP-14 and VEGF (Abcam, Cambridge, UK) at $4{ }^{\circ} \mathrm{C}$ overnight. Then, the blot was washed with TBST three times for $15 \mathrm{~min}$ each and incubated with secondary antibodies (Abcam). GAPDH was used as an internal reference. Immunoreactive bands were developed with an enhanced chemiluminescence kit (Bio-Rad) following the manufacturer's instruction and then detected with a ChemiDoc ${ }^{\mathrm{TM}}$ Imaging System (Bio-Rad).

Orthotopic osteosarcoma xenograft tumour mouse model. The care and treatment procedures for the experimental animals in this study were in accordance with the ethical standards of the Declaration of Helsinki and the national and international guidelines of the People's Republic of China. The study was approved by the ethical committee of Zhongnan Hospital of Wuhan University. Ten 4-week-old male nude mice (BALb/c) were obtained from Beijing HFK Bioscience Co., Ltd. (Beijing, China). Orthotopic osteosarcoma xenograft tumours were produced using a subperiosteal injection method based on the previously published literature ${ }^{34,35}$. Briefly, 143B cells (4-6 passages) were resuspended in PBS to a final concentration of $3 \times 10^{7} \mathrm{cells} / \mathrm{ml}$. Animals were anaesthetized by intraperitoneal injection of pentobarbital $(80 \mathrm{mg} / \mathrm{kg}) .100 \mu \mathrm{l}$ of prepared cell suspension containing $3 \times 10^{6}$ cells was injected subperiosteally into the right proximal lateral tibia using a 25 -gauge needle. The cell suspension was prevented from oozing out by applying gentle pressure to the injection point with cotton swab for 10 seconds. Then, the animals were divided into two groups: the miR-302b agomir treatment group and the agomir control group. Seven days after tumour inoculation, the xenograft tumours were approximately at $100 \mathrm{~mm}^{3}$. The miR-302b agomir or agomir control ( $5 \mathrm{nmol}$ in $0.1 \mathrm{ml}$ per mouse) was injected intratumourally every three days. Tumour growth was observed every day after tumour inoculation. A Vernier caliper was used to measure the length and width of the tumour. Tumour volume $\left(\mathrm{mm}^{3}\right)$ was calculated using the following equation: length $\times$ width $^{2} \times 0.5$. Digital plain-film X-ray images covering the entire affected hind limbs were taken by Digital Diagnost (Philips Healthcare, Netherlands) to evaluate the orthotopic tumour formed by the 143B cells. Typical images of osteolysis, osteosclerosis, periosteal reaction and soft tissue mass were regarded as the characteristics of osteosarcoma.

Haematoxylin and eosin (H\&E) staining. After being sacrificed, mice were anatomized to obtain the tumour tissue from the hind limbs and the lung tissue. All the tissue samples were fixed in paraformaldehyde, embedded in paraffin, and sectioned with a microtome into $5-\mu \mathrm{m}$-thick sections using routine methods. The sections were deparaffinized with xylene for $10 \mathrm{~min}$ and rehydrated with $100 \%$ ethanol, $96 \%$ ethanol, $80 \%$ ethanol, $70 \%$ ethanol, and $\mathrm{H}_{2} \mathrm{O}, 5 \mathrm{~min}$ for each step. The sections were stained with $10 \%$ haematoxylin (Sigma-Aldrich) for $7 \mathrm{~min}$, washed with tap water for $10 \mathrm{~min}$, and stained for $5 \mathrm{~min}$ in $1 \%$ eosin (Sigma-Aldrich) containing $0.2 \%$ glacial acetic acid. Then, the slides were dehydrated in ethanol with graded concentrations of $70 \%, 80 \%, 96 \%$, and $100 \%, 2 \mathrm{~min}$ for each step, followed by 5-10 $\mathrm{min}$ in xylene. The sections were observed and photographed using a light microscope (Leica, Germany).

Statistical analysis. All data were subjected to statistical analysis using SPSS 17.0. Measurement data are expressed as the mean \pm SD from at least three independent experiments. Student's $t$-test or one-way ANOVA was applied to determine the differences. $P<0.05$ was considered statistically significant.

\section{References}

1. Senerchia, A. A. et al. Results of a randomized, prospective clinical trial evaluating metronomic chemotherapy in nonmetastatic patients with high-grade, operable osteosarcomas of the extremities: A report from the Latin American Group of Osteosarcoma Treatment. Cancer 123, 1003-1010, https://doi.org/10.1002/cncr.30411 (2017).

2. Rothermundt, C. et al. Follow-up practices for high-grade extremity Osteosarcoma. BMC cancer 16, 301, https://doi.org/10.1186/ s12885-016-2333-y (2016).

3. Wang, S. et al. A predictive model to estimate the pretest probability of metastasis in patients with osteosarcoma. Medicine $\mathbf{9 6}$, e5909, https://doi.org/10.1097/MD.0000000000005909 (2017).

4. Flores, R. J. et al. A novel prognostic model for osteosarcoma using circulating CXCL10 and FLT3LG. Cancer 123, 144-154, https:// doi.org/10.1002/cncr.30272 (2017).

5. Chang, L., Shrestha, S., LaChaud, G., Scott, M. A. \& James, A. W. Review of microRNA in osteosarcoma and chondrosarcoma. Medical oncology 32, 613, https://doi.org/10.1007/s12032-015-0613-z (2015).

6. Fenger, J. M. et al. MiR-9 is overexpressed in spontaneous canine osteosarcoma and promotes a metastatic phenotype including invasion and migration in osteoblasts and osteosarcoma cell lines. BMC cancer 16, 784, https://doi.org/10.1186/s12885-016-2837-5 (2016).

7. Wang, J., Pang, W., Zuo, Z., Zhang, W. \& He, W. MicroRNA-520b Suppresses Proliferation, Migration, and Invasion of Spinal Osteosarcoma Cells Via Downregulation of Frizzled-8. Oncology research, https://doi.org/10.3727/096504017X14873430389189 (2017). 
8. Hirahata, M. et al. PAI-1, a target gene of miR-143, regulates invasion and metastasis by upregulating MMP-13 expression of human osteosarcoma. Cancer medicine 5, 892-902, https://doi.org/10.1002/cam4.651 (2016).

9. Huang, G., Nishimoto, K., Zhou, Z., Hughes, D. \& Kleinerman, E. S. miR-20a encoded by the miR-17-92 cluster increases the metastatic potential of osteosarcoma cells by regulating Fas expression. Cancer research 72, 908-916, https://doi.org/10.1158/00085472.CAN-11-1460 (2012).

10. Hu, H., Zhang, Y., Cai, X. H., Huang, J. F. \& Cai, L. Changes in microRNA expression in the MG-63 osteosarcoma cell line compared with osteoblasts. Oncology letters 4, 1037-1042, https://doi.org/10.3892/ol.2012.866 (2012).

11. Zhang, Y. et al. Epirubicin-mediated expression of miR-302b is involved in osteosarcoma apoptosis and cell cycle regulation. Toxicology letters 222, 1-9, https://doi.org/10.1016/j.toxlet.2013.06.242 (2013).

12. Wang, L. et al. miR-302b suppresses cell invasion and metastasis by directly targeting AKT2 in human hepatocellular carcinoma cells. Tumour biology: the journal of the International Society for Oncodevelopmental Biology and Medicine 37, 847-855, https://doi. org/10.1007/s13277-015-3330-5 (2016).

13. Pandima Devi, K. et al. Targeting miRNAs by polyphenols: Novel therapeutic strategy for cancer. Seminars in cancer biology, https:// doi.org/10.1016/j.semcancer.2017.02.001 (2017).

14. Muluhngwi, P. \& Klinge, C. M. Identification of miRNAs as biomarkers for acquired endocrine resistance in breast cancer. Molecular and cellular endocrinology, https://doi.org/10.1016/j.mce.2017.02.004 (2017).

15. Cataldo, A. et al. miR-302b enhances breast cancer cell sensitivity to cisplatin by regulating E2F1 and the cellular DNA damage response. Oncotarget 7, 786-797, https://doi.org/10.18632/oncotarget.6381 (2016).

16. Wang, L. et al. miRNA-302b suppresses human hepatocellular carcinoma by targeting AKT2. Molecular cancer research: MCR 12, 190-202, https://doi.org/10.1158/1541-7786.MCR-13-0411 (2014).

17. Khodayari, N., Mohammed, K. A., Lee, H., Kaye, F. \& Nasreen, N. MicroRNA-302b targets Mcl-1 and inhibits cell proliferation and induces apoptosis in malignant pleural mesothelioma cells. American journal of cancer research 6, 1996-2009 (2016).

18. Liu, F. Y. et al. miR-302b regulates cell cycles by targeting CDK2 via ERK signaling pathway in gastric cancer. Cancer medicine $\mathbf{5}$, 2302-2313, https://doi.org/10.1002/cam4.818 (2016).

19. Chen, P. H. et al. MicroRNA-302b-inhibited E2F3 transcription factor is related to all trans retinoic acid-induced glioma cell apoptosis. Journal of neurochemistry 131, 731-742, https://doi.org/10.1111/jnc.12820 (2014).

20. Cai, D., He, K., Chang, S., Tong, D. \& Huang, C. MicroRNA-302b Enhances the Sensitivity of Hepatocellular Carcinoma Cell Lines to 5-FU via Targeting Mcl-1 and DPYD. International journal of molecular sciences 16, 23668-23682, https://doi.org/10.3390/ ijms161023668 (2015).

21. Zhang, M. et al. miR-302b is a potential molecular marker of esophageal squamous cell carcinoma and functions as a tumor suppressor by targeting ErbB4. Journal of experimental \& clinical cancer research: CR 33, 10, https://doi.org/10.1186/1756-9966-3310 (2014).

22. Li, X., Cui, Q., Kao, C., Wang, G. J. \& Balian, G. Lovastatin inhibits adipogenic and stimulates osteogenic differentiation by suppressing PPARgamma2 and increasing Cbfa1/Runx2 expression in bone marrow mesenchymal cell cultures. Bone 33, 652-659 (2003).

23. Kanatani, N. et al. Cbf beta regulates Runx2 function isoform-dependently in postnatal bone development. Developmental biology 296, 48-61, https://doi.org/10.1016/j.ydbio.2006.03.039 (2006).

24. Sadikovic, B. et al. Expression analysis of genes associated with human osteosarcoma tumors shows correlation of RUNX2 overexpression with poor response to chemotherapy. BMC cancer 10, 202, https://doi.org/10.1186/1471-2407-10-202 (2010).

25. Li, N. et al. RUNX2 and Osteosarcoma. Anti-cancer agents in medicinal chemistry 15, 881-887 (2015).

26. Qin, L., Zhang, Y., Lin, J., Shentu, Y. \& Xie, X. MicroRNA-455 regulates migration and invasion of human hepatocellular carcinoma by targeting Runx2. Oncology reports 36, 3325-3332, https://doi.org/10.3892/or.2016.5139 (2016).

27. Zhu, Y., Zhao, H., Feng, L. \& Xu, S. MicroRNA-217 inhibits cell proliferation and invasion by targeting Runx2 in human glioma. American journal of translational research 8, 1482-1491 (2016).

28. van der Deen, M. et al. MicroRNA-34c inversely couples the biological functions of the runt-related transcription factor RUNX2 and the tumor suppressor 533 in osteosarcoma. The Journal of biological chemistry 288, 21307-21319, https://doi.org/10.1074/jbc. M112.445890 (2013).

29. Zhang, C., Long, F., Wan, J., Hu, Y. \& He, H. MicroRNA-205 acts as a tumor suppressor in osteosarcoma via targeting RUNX2. Oncology reports 35, 3275-3284, https://doi.org/10.3892/or.2016.4700 (2016).

30. Zhang, R. et al. MiR-30a regulates the proliferation, migration, and invasion of human osteosarcoma by targeting Runx2. Tumour biology: the journal of the International Society for Oncodevelopmental Biology and Medicine 37, 3479-3488, https://doi.org/10.1007/ s13277-015-4086-7 (2016).

31. He, Y., Meng, C., Shao, Z., Wang, H. \& Yang, S. MiR-23a functions as a tumor suppressor in osteosarcoma. Cellular physiology and biochemistry: international journal of experimental cellular physiology, biochemistry, and pharmacology 34, 1485-1496, https://doi. org/10.1159/000366353 (2014).

32. Livak, K. J. \& Schmittgen, T. D. Analysis of relative gene expression data using real-time quantitative PCR and the 2 (-Delta Delta C (T)) Method. Methods 25, 402-408, https://doi.org/10.1006/meth.2001.1262 (2001).

33. Zhu, R. et al. Ascl2 knockdown results in tumor growth arrest by miRNA-302b-related inhibition of colon cancer progenitor cells. PloS one 7, e32170, https://doi.org/10.1371/journal.pone.0032170 (2012).

34. Yu, Z. et al. Establishment of reproducible osteosarcoma rat model using orthotopic implantation technique. Oncology reports 21, $1175-1180$ (2009).

35. Zhao, Y. et al. Genetically engineered pre-microRNA-34a prodrug suppresses orthotopic osteosarcoma xenograft tumor growth via the induction of apoptosis and cell cycle arrest. Scientific reports 6, 26611, https://doi.org/10.1038/srep26611 (2016).

\section{Acknowledgements}

The authors thank Prof Ansong Ping and Prof Jun Lei from Department of Orthopaedics, Zhongnan Hospital of Wuhan University, China, for assisting in tissue collection. This work is supported by a grant from the National Natural Science Foundation of China (grant number 81571811). The funders had no role in the study design, data collection and analysis, decision to publish, or preparation of the manuscript.

\section{Author Contributions}

L.C., Z.M.D., X.B.Z., C.H., and Y.L.X. conceived and designed the experiments and reviewed manuscript. Y.L.X. and W.C.S. performed the experiments and contributed reagents/materials/analysis tools. Y.L.X., W.C.S. and Z.M.D. analysed the results, wrote the manuscript, and prepared figures and/or tables.

Additional Information

Competing Interests: The authors declare that they have no competing interests. 
Publisher's note: Springer Nature remains neutral with regard to jurisdictional claims in published maps and institutional affiliations.

(c) (i) Open Access This article is licensed under a Creative Commons Attribution 4.0 International License, which permits use, sharing, adaptation, distribution and reproduction in any medium or format, as long as you give appropriate credit to the original author(s) and the source, provide a link to the Creative Commons license, and indicate if changes were made. The images or other third party material in this article are included in the article's Creative Commons license, unless indicated otherwise in a credit line to the material. If material is not included in the article's Creative Commons license and your intended use is not permitted by statutory regulation or exceeds the permitted use, you will need to obtain permission directly from the copyright holder. To view a copy of this license, visit http://creativecommons.org/licenses/by/4.0/.

(c) The Author(s) 2017 